\title{
Integration and Weighing of Omics Data for Obesity
}

\author{
Caroline Brettfeld ${ }^{1}$, Ales Maver ${ }^{2}$, Eva Aumuller ${ }^{1}$, Borut Peterlin ${ }^{2}$ and Alexander G Haslberger ${ }^{1 *}$
}

${ }^{1}$ Department for Nutrition Sciences, University of Vienna, Austria

${ }^{2}$ Department of Human Genetics, University of Ljubljana, Austria

\begin{abstract}
Objective: OMICs research has become of great interest over the last years and enabled the research community to acquisition an increasing amount of data. In a prior study by our group, we have employed a novel positional integrative approach. For this second study we utilized the same integration method but weighed each individual data source trying to verify our already found regions and/or identify new gene regions of interest for obesity.

Method: In contrast to previous methodologies employed for integration of heterogeneous OMIC data, we based the integration on genomic positions of alterations in human disease and employed an additional weighing step. A data search for various types of studies on Obesity (genome-wide association, meta-analysis, transcriptomic, proteomic studies and epigenetic studies) was conducted to establish the initial data set. For this study, five different weighing settings were used, to individually double the input of genomic data, transcriptomic data, proteomic data,
\end{abstract} microRNA data and epigenetic data in comparison to all the other data sources.

Results and discussion: The analysis identified ten gene regions (ATP5O, ALK7, GAPDH, IFFO1, NCAPD2, DDX50, MAOB, ATM, STOX1 and PRRC2A). ATP5O, ALK7 and GADPH were also identified in our prior study as the highest scoring gene regions and prove to be consistent in our data set. Even though, the ten high ranked and discussed genes could not be directly linked to obesity nine of them are associated with Type 2 Diabetes or a neurodegenerative disease. Both disorders show a higher prevalence in obese individuals compared to lean.

Conclusion: In this study, we applied a new method of positional integrational analysis of different OMIC-layers and an additional validation step through weighing. our study provides a basis for further research to elucidate underlying mechanisms of these associations and identify new targets for preventive and therapeutic interventions.

Keywords: Obesity; OMIC-data integration; Data weighing

\section{Objective}

In the last years emerging fields of biology were added the suffix '-omics' onto previously used terms, such as genomics, transcriptomics, proteomics and epigenomics. The related suffix -ome is used to address the objects of study of such fields and refers to the collective characterization of all molecules or mechanisms on a distinct level of metabolic processes [1]. Analysis of OMICs Data aims to investigate and identify the pathways and biological processes most affected in the datasets and to highlight potential biomarkers and drug targets. OMICs research has become of great interest over the last years and enabled the research community to acquisition an increasing amount of data. These data comprehensively measure complex and multilayered molecular networks and provide a snapshot of biological processes in a cell, organism, or their communities. Functional analysis is already used in personalized medicine, patient stratification and drug repositioning, in many areas of public health.

OMICs data analysis depends on knowledge of pathway maps, protein interactions, functional ontologies, and gene-disease associations, which can be achieved by advanced analytical algorithms for enrichment or network analysis [2-4].

Obesity $\left(\mathrm{BMI}>30 \mathrm{~kg} / \mathrm{m}^{2}\right)$ has become an enormous public health problem that affects millions of people all around the globe [5-7]. Obesity is involved in the pathogenesis of diseases like hypertension, cardiovascular events, metabolic syndrome, diabetes mellitus type $2[8,9]$, and different types of cancer [10-12]. Over the last decade studies have shown that the etiology of obesity is multifactorial and includes a combination of genetic and environmental factors that influence the balance between energy intake and energy release [1316]. Tremendous effort is made to better understand the complex genetics of human obesity and utilize the discovered knowledge about the signaling pathways of obesity to design obesity drugs and novel therapies $[17,18]$. Obesity appears to be in part under genetic control, with a multitude of genes, most with a modest effect, contributing to an individual's predisposition to obesity [19]. It is estimated that $40 \%$ to $70 \%$ of human fat mass is heritable [20]. Genome-wide scans have led to the identification of several chromosome regions that are likely to harbor genes determining susceptibility and indicate that at least 32 genes contribute to common forms of obesity. These genes are thought to be related through the earlier discussed biochemical mechanisms that are implicated in metabolic diseases.

One example is the transcription factor 7-like 2 (TCF7L2) gene. TCF7L2 encrypts a transcription factor that is implicated in the Wnt signaling pathway and is found to be identified in many tissues, including those with a key metabolic role [21]. Though various cell or animal studies showed persuasive evidence for a powerful association of TCF7L2 into pancreatic beta cell mechanisms including insulin production and processing [22], some studies also introduced the possibility that the beta cell dysfunction related to TCF7L2 was indirect and was the final result of disruptions in liver, brain, or gut $[23,24]$.

*Corresponding author: Alexander G Haslberger, Department for Nutrition Sciences, University of Vienna, Austria, Tel: +43 6991 2211212; E-mail: alexander.haslberger@univie.ac.at

Received July 12, 2016; Accepted July 21, 2016; Published July 27, 2016

Citation: Brettfeld C, Maver A, Aumuller E, Peterlin B, Haslberger AG (2016) Integration and Weighing of Omics Data for Obesity. J Diabetes Metab 7: 690. doi: 10.4172/2155-6156.1000690

Copyright: (c) 2016 Brettfeld C, et al. This is an open-access article distributed under the terms of the Creative Commons Attribution License, which permits unrestricted use, distribution, and reproduction in any medium, provided the original author and source are credited. 
It has been identified that the strongest genetic association with risk to polygenic obesity are single-nucleotide variants in intron 1 and 2 of the FTO (fat mass and obesity associated) gene [25,26]. FTO has attracted interest as it was identified by genome-wide studies as a susceptibility gene for body mass index (BMI) and T2DM. BMI is a measure of obesity, strongly suggesting that the association of FTO gene variations with T2DM risk is secondary to effects on BMI. Extensive molecular studies using experimental animal models, "forward genetics" (e.g. generation of random mutations and screening for phenotypes of interest), and "reverse genetics" (e.g. generation mutations in a gene of interest and observing the resulting phenotypes) have helped identify critical pathways that regulate body fat and food intake [27]. An example is the central melanocortin pathway that has a fundamental importance in mammalian energy balance [28]. As a result of these extensive efforts, human ortholog genes were identified as well [29].

While several genes have been linked to excess weight gain, the existence of these genes cannot explain the rapidly growing prevalence of obesity. Many explanations for this missing heritability have been investigated in recent years, including much larger numbers of variants of smaller effect yet to be found, rarer variants that are poorly detected by available genotyping arrays or structural variants poorly depicted by existing arrays. Also low power to detect gene-gene interactions and inadequate accounting for shared environment among relatives. Therefore, epigenetics literally means "on top of or in addition to genetics" became of greater interest in the last couple of years. It is defined as the study of mechanisms or pathways that initiate and maintain heritable patterns of gene expression and gene function without changing the DNA sequence. In parallel to the term "genome" that defines the complete set of genetic information contained in the DNA of an organism, "epigenome" generally refers to the complete set of characteristics of epigenetic pathways in an organism. Epigenetic mechanisms involve chemical processes such as DNA methylation, covalent modifications to histones, and chromatin folding that can change gene expression without changing the DNA sequence [30]. Epigenetic alterations can sometimes promote expression of a gene that has typically been silent or silence a gene that is usually active. A well studied example is the Dutch famine that describes the effects of prenatal exposure to a famine on health in later life. It was found that undernutrition during gestation affects health in later life and that this effects depend on the time point of exposure [31].

For common multifactorial traits like obesity, GWAS have been very informative but do not address the heritable risk sufficiently. Rarer variants or epigenetic investigations are important but in general, more integrated approaches are needed in which environmental risk factors are considered and combined with functional genomic analyses.

We already utilized an approach for integration of such multiorigin data based on positions of genetic alterations occurring in obesity $[32,33]$. For this second study we utilized the same data set but weighed each individual data source double and combined them with all the other data sources weighed single, which means we conducted 5 different analysis (genomic, transcriptomic, proteomic, RNA data, epigenetic) with the integration tool trying to verify our already found regions and/or identify new gene regions of interest.

\section{Method}

We utilized the same data set we used for our prior study [32] which we generated through a search for various types of studies on
Obesity (genome-wide association, meta-analysis, transcriptomic, proteomic studies, microRNA data and epigenetic studies) in online repositories, using GWAS Central (http://www.gwascentral.org) Medline database (www.ncbi.nlm.nih.gov/pubmed/) with search string (obesity) and (transcriptome OR proteome OR genome-wide OR microarray OR profiling OR epigenetics). Additionally, Gene Expression Omnibus (GEO) repository (http://www.ncbi.nlm.nih.gov/ geo/), ArrayExpress (http://www.ebi.ac.uk/arrayexpress/) and Stanford Microarray Database (http://smd.stanford.edu) were searched up to find more suitable sources of data for inclusion in our data set. Studies that were conducted in adults (male and female) of any ethnic origin were included in the data set. Studies conducted in animals, children or elderly, and studies missing information of gender, age, study design and ethnicity were excluded from the data set. The data search was started from the Jan 01, 2000 to Jan 01, 2014 [32].

\section{GWAS and meta-analysis}

Data from 20 GWA Studies and two Meta-Analysis were obtained and are listed in Table 1 [33-54].

\section{Transcriptional data}

Raw data on transcriptomic alterations in adipose, omental, and subcutaneous fat, as well as in liver and in skeletal muscle were obtained from GEO repository. Transcriptomic alterations were treated as separate data sets to account for possible differences in transcriptional alterations observed in these tissue samples [55-62].

\section{Proteomic, microRNA data and epigenetics}

We have included three studies investigating proteomic, microRNA and epigenetic alterations by Arner et al. [61], Farha et al. [63] and Barres et al. [64]. The three studies were treated as separate data sets to account for their different biological layer and the different tissues samples that were utilized for the analysis.

The positional integration approach was introduced by Maver et al. [65] in 2011. To utilize the bioinformatical tool the p-value of each signal is transformed to $-\log _{10} \mathrm{p}$ value and all annotations are converted to coordinate positions. Then the tool arranges the significant signals from every type of study into the selected intervals on the DNA backbone [65]. The tool allows the user to weigh the different data sets and select the kb length. Weighing settings were adjusted and a $50 \mathrm{~kb}$ length was selected. For this study, 5 different weighing settings were used, to individually double the input of genomic data, transcriptomic data, proteomic data, microRNA data and epigenetic data in comparison to all the other data sources. Our initial data assembly was subdivided into $50 \mathrm{~kb}$ regions, and signals from afore mentioned studies were arranged on the genomic backbone into the corresponding regions according to their genomic position.

Evaluation was performed by searching for corresponding genes in the different weighed data sets and a direct association of genes located in top regions selected by the integration process and obesity in the Medline database (www.ncbi.nlm.nih.gov/pubmed). The search was performed on articles that appeared in Medline using the following search string: 'Obesity AND Gene,' where 'Gene' entry represented candidate genes located in the regions discovered by the integration process.

Additionally functional profiles of genes located in the set of top region have been profiled using Gene Ontology (GO, http:// www.geneontology.org [66]) and Kyoto Encyclopedia of Genes and Genomes (KEGG, http://www.genome.jp/kegg/ [67]). 
Citation: Brettfeld C, Maver A, Aumuller E, Peterlin B, Haslberger AG (2016) Integration and Weighing of Omics Data for Obesity. J Diabetes Metab 7: 690. doi: 10.4172/2155-6156.1000690

Page 3 of 11

\begin{tabular}{|c|c|c|c|c|}
\hline Name & Number of Individuals & Analytical Method & $\begin{array}{l}\text { Total } \\
\text { Markers } \\
\text { Imported }\end{array}$ & Related citations \\
\hline $\begin{array}{l}\text { GWAS of adiposity- related } \\
\text { heterogeneity in patterns of type II } \\
\text { diabetes susceptibility }\end{array}$ & $\begin{array}{l}\text { Initial Panel 4,862 (Cases 1,924, Controls } \\
\text { 2,938) Second Panel 9,103 (Cases 3,757, } \\
\text { Controls 5,346) }\end{array}$ & Affymetrix 393,453 & 5 & Timpson et al. [33] Hindorff et al. [34] \\
\hline GWAS of type II diabetes mellitus & 5,975 (Cases 531, Controls 5,275) & Hар300 & 55 & $\begin{array}{l}\text { Steinthorsdottir et al. [35] Johnson et } \\
\text { al. [36] }\end{array}$ \\
\hline $\begin{array}{l}\text { GWAS of waist circumference in } \\
\text { individuals of Caucasian descent }\end{array}$ & $\begin{array}{l}\text { Initial Panel 31,373 Replication Panel } \\
38,641\end{array}$ & $\begin{array}{l}\text { Affymetrix and Illumina up to } \\
512,349\end{array}$ & 7 & $\begin{array}{l}\text { Heard-Costa et al. [37] Hindorff et al. } \\
{[34]}\end{array}$ \\
\hline GWAS of extreme obesity & 3,972 (Cases 775, Controls 3,197) & Illumina 457,251 & 13 & Cotsapas et al. [38] Hindorff et al. [34] \\
\hline GWAS of body mass index & 10,657 & Affymetrix 490,032 & 1 & Frayling et al. [39] Hindorff et al. [34] \\
\hline $\begin{array}{l}\text { GWAS of body mass index in } \\
\text { individuals of European descent }\end{array}$ & 16,876 & Affymetrix 344,883 & 2 & Loos et al. [40] Hindorff et al. [34] \\
\hline GWAS of body mass index & 32,387 & $\begin{array}{l}\text { Illumina and Affymetrix } \\
2,399,588\end{array}$ & 11 & Willer et al. [41] Hindorff et al. [34] \\
\hline $\begin{array}{l}\text { GWAS of body mass index and } \\
\text { weight }\end{array}$ & 80,969 & Illumina 305,846 & 17 & Thorleifsson et al. [42] Hindorff et al. [34] \\
\hline $\begin{array}{l}\text { GWAS of body mass index and waist } \\
\text { circumference in the Framingham } \\
\text { Heart Study }\end{array}$ & 1,341 & Affy100K & 34 & $\begin{array}{l}\text { Fox et al. [43] Johnson et al. [36] } \\
\text { Hindorff et al. [34] }\end{array}$ \\
\hline GWAS of obesity-related traits & 4,298 & Affy $10 \mathrm{~K}$ Affy $500 \mathrm{~K}$ & 37 & $\begin{array}{l}\text { Scuteri et al. [44] Johnson et [36] al. } \\
\text { Hindorff et al. [34] }\end{array}$ \\
\hline GWAS of weight and body mass index & 3,925 & Illumina 318,237 & 6 & Johansson et al. [45] Hindorff et al. [34] \\
\hline GWAS of extreme obesity & $\begin{array}{l}\text { Initial Panel 5,373 (Cases 2,633, Controls } \\
\text { 2,740) Replication Panel } 29,181\end{array}$ & Illumina 545,349 & 4 & $\begin{array}{l}\text { Paternoster et al. [46] Hindorff } \\
\text { et al. [34] }\end{array}$ \\
\hline GWAS of obesity & $\begin{array}{l}\text { Initial Panel 1,060 (Cases 520, Controls } \\
\text { 540) Replication Panel 1,196 }\end{array}$ & Illumina $\sim 550,000$ & 4 & Wang et al. [47] Hindorff et al. [34] \\
\hline GWAS of obesity & $\begin{array}{l}\text { Initial Panel } 327 \text { (Cases 164, Controls 163) } \\
\text { Replication Panel 10,337 (Cases 4,674, } \\
\text { Controls 5,663) }\end{array}$ & Affymetrix 406,177 & 2 & Jiao et al. [48] Hindorff et al. [34] \\
\hline GWAS of body mass index & $\begin{array}{l}\text { Initial Panel 1,715 Replication Panel } \\
3,274\end{array}$ & Affymetrix 746,626 & 2 & Ng et al. [49] Hindorff et al. [34] \\
\hline GWAS of body mass index & $\begin{array}{l}\text { Initial Panel 123,865 Replication Panel } \\
125,931\end{array}$ & $\begin{array}{l}\text { Affymetrix, Illumina and } \\
\text { Perlegen } \sim 2.8 \text { million } \\
\text { (imputed) }\end{array}$ & 38 & Speliotes et al. [50] Hindorff et al. [34] \\
\hline Meta-analysis of extreme obesity & $\begin{array}{l}\text { Initial Panel 2,258 Replication Panel A } \\
\text { 5,829 Replication Panel B 31,182 }\end{array}$ & $\begin{array}{l}\text { Affymetrix \& Illumina } \\
1,596,878 \text { (imputed) }\end{array}$ & 5 & Scherag et al. [51] Hindorff et al. [34] \\
\hline $\begin{array}{l}\text { GWAS of adult body mass index in a } \\
\text { British population }\end{array}$ & 9,377 & $\begin{array}{l}\text { Affymetrix GeneChip } \\
\text { Mapping 500K Illumina } \\
\text { Infinium HumanHap550 }\end{array}$ & 528,865 & Strachan et al. [52] \\
\hline GWAS of obesity & 10,391 & Illumina $1,283,957$ (imputed) & 1 & Dorajoo et al. [53] Hindorff et al. [34] \\
\hline $\begin{array}{l}\text { Meta-analysis of GWAS informative } \\
\text { for adult waist circumference and } \\
\text { waist- hip ratio }\end{array}$ & $\begin{array}{l}\text { Initial Panel 38,580 Replication Panel } \\
\text { 102,064 }\end{array}$ & $\begin{array}{l}\text { Affymetrix and Illumina } \\
2,573,738 \text { (imputed) }\end{array}$ & 3 & Lindgren et al. [54] Hindorff et al. [34] \\
\hline
\end{tabular}

Table 1: List of GWAS and meta-analysis for initial data set.

\section{Results and Discussion}

The five different analysis results are shown in Tables 2 to 7 and the same results are depicted in Figure 1. The positional integration approach yielded a prioritized list of genomic region, where the regions containing the highest accumulation of diverse biological alterations in obesity rank highest. We identified 49 high scoring gene regions (Tables 2 and 3) with the doubled input of genomic data and the normal weighed transcriptomic, proteomic, microRNA level and epigenetic. The transcriptomic data weighed double resulted in 132 high scoring genes (Table 4). Table 5 depicts 40 high scoring gene regions for the double weighed proteomic data and the normal weighed genomic, transcriptomic, microRNA level and epigenetic data. Table 6 depicts 63 high scoring gene regions for the double weighed microRNA. The double weighed epigenetic with the single weighed other data sources showed 24 high scoring gene regions (Table 7).
We selected ten gene regions that were exhibiting the highest scores and found in more than one analysis results (ATP5O, ALK7, GADPH, IFFO1, NCAPD2, DDX50, MAOB, ATM, STOX1 and PRRC2A). In a prior study the eight highest scoring gene regions (ATP5O, ALK7, CR1, CR2, S100, GAPDH, TLR1 and TLR6) were discussed for their association to obesity. Since ATP5O, ALK7 and GADPH were among the previously discussed gene regions, the results of the second analysis prove to be consistent with our first study [32].

All of the remaining 7 identified gene regions (IFFO1, NCAPD2, DDX50, MAOB, ATM, STOX1 and PRRC2A) were also identified in our prior study [32], however, the gene regions were not discussed as they where not identified to be highest scoring regions but can be identified in the supplementary data.

The two genes that were found in all high scoring tables were ATP5O and ACVR1C or ALK7. GAPDH, IFFO1 and NCAPD2 were 
Citation: Brettfeld C, Maver A, Aumuller E, Peterlin B, Haslberger AG (2016) Integration and Weighing of Omics Data for Obesity. J Diabetes Metab 7: 690. doi: 10.4172/2155-6156.1000690

Page 4 of 11

\begin{tabular}{|c|c|c|c|c|}
\hline $\begin{array}{c}\text { Identificatio } \\
\text { n No. }\end{array}$ & Title & $\begin{array}{l}\text { Number of } \\
\text { Individuals }\end{array}$ & $\begin{array}{l}\text { Analytical } \\
\text { Method }\end{array}$ & Refernce \\
\hline GSE20950 & $\begin{array}{l}\text { Morbidly obese } \\
\text { insulin-resistant } \\
\text { patients: omental } \\
\text { and subcutaneous } \\
\text { adipose tissue }\end{array}$ & 10 & $\begin{array}{l}\text { Affymetrix } \\
\text { Human } \\
\text { Genome U133 } \\
\text { Plus 2.0 Array } \\
\text { \& real time } \\
\text { PCR }\end{array}$ & $\begin{array}{l}\text { Hardy, Perugini, } \\
\text { Nicoloro, } \\
\text { Gallagher- } \\
\text { Dorval et al. [55] }\end{array}$ \\
\hline GSE27951 & $\begin{array}{l}\text { Adipogenesis } \\
\text { and obesity: } \\
\text { subcutaneous } \\
\text { adipose tissue } \\
\text { (HG-U133_Plus_2) }\end{array}$ & 20 & $\begin{array}{l}\text { Affymetrix } \\
\text { Human } \\
\text { Genome U133 } \\
\text { Plus 2.0 Array }\end{array}$ & $\begin{array}{l}\text { Keller, Gburcik, } \\
\text { Petrovic, } \\
\text { Gallagher et al. } \\
{[56]}\end{array}$ \\
\hline GSE15524 & $\begin{array}{l}\text { Morbid obesity: } \\
\text { subcutaneous and } \\
\text { omental adipose } \\
\text { tissues }\end{array}$ & 11 & $\begin{array}{l}\text { CodeLink } \\
\text { UniSet Human } \\
\text { 20K I Bioarray }\end{array}$ & $\begin{array}{l}\text { MacLaren, Cui, } \\
\text { Lu, Simard et } \\
\text { al. [57] }\end{array}$ \\
\hline GSE474 & $\begin{array}{l}\text { Obesity and fatty } \\
\text { acid oxidation }\end{array}$ & 16 & $\begin{array}{l}\text { Affymetrix } \\
\text { Human } \\
\text { Genome } \\
\text { U133A Array }\end{array}$ & $\begin{array}{l}\text { Park, Berggren, } \\
\text { Hulver, Houmard } \\
\text { et al. [58] }\end{array}$ \\
\hline GSE15773 & $\begin{array}{l}\text { Obesity-associated } \\
\text { insulin resistance } \\
\text { independent of } \\
\text { BMI: omental and } \\
\text { subcutaneous } \\
\text { adipose tissues }\end{array}$ & 20 & $\begin{array}{l}\text { Affymetrix } \\
\text { Human } \\
\text { Genome U133 } \\
\text { Plus 2.0 Array }\end{array}$ & $\begin{array}{l}\text { Hardy, Perugini, } \\
\text { Nicoloro, } \\
\text { Gallagher- } \\
\text { Dorval et al. [55] }\end{array}$ \\
\hline GSE15653 & $\begin{array}{l}\text { Obese patients with } \\
\text { and without type } 2 \\
\text { diabetes: liver }\end{array}$ & $\begin{array}{c}18 \text { (Cases } \\
13, \text { Controls } \\
5)\end{array}$ & $\begin{array}{l}\text { Affymetrix } \\
\text { Human } \\
\text { Genome } \\
\text { U133A Array }\end{array}$ & $\begin{array}{l}\text { Pihlajamäki, } \\
\text { Boes, Kim, } \\
\text { Dearie et al. [59] }\end{array}$ \\
\hline GSE22435 & $\begin{array}{l}\text { Expression of } \\
\text { Splicing Factor } \\
\text { Genes is Reduced } \\
\text { in Human Obesity } \\
\text { and Contributes } \\
\text { to Enhanced } \\
\text { Lipogenesis }\end{array}$ & $\begin{array}{c}17 \text { (Cases } \\
7, \text { Controls } \\
10)\end{array}$ & $\begin{array}{l}\text { Affymetrix } \\
\text { Human } \\
\text { Genome U133 } \\
\text { Plus 2.0 Array }\end{array}$ & $\begin{array}{l}\text { Pihlajamäki, } \\
\text { Lerin, Itkonen, } \\
\text { Boes et al. [60] }\end{array}$ \\
\hline GSE25401 & $\begin{array}{l}\text { Adipose Tissue } \\
\text { MicroRNAs as } \\
\text { Regulators of } \\
\text { CCL2 Production } \\
\text { in Human Obesity } \\
\text { [gene expression] }\end{array}$ & $\begin{array}{c}56 \text { (Cases } \\
30 \\
\text { Conroles } \\
26)\end{array}$ & $\begin{array}{l}\text { Affymetrix } \\
\text { Human Gene } \\
\text { 1.0 ST Array }\end{array}$ & $\begin{array}{l}\text { Arner, Mejhert, } \\
\text { Kulyté, Balwierz } \\
\text { et al. [61] }\end{array}$ \\
\hline GSE25402 & $\begin{array}{l}\text { Adipose Tissue } \\
\text { MicroRNAs as } \\
\text { Regulators of } \\
\text { CCL2 Production } \\
\text { in Human Obesity }\end{array}$ & 56 & $\begin{array}{l}\text { Affymetrix } \\
\text { Human Gene } \\
\text { 1.0 ST Array } \\
\text { [transcript } \\
\text { (gene) version] }\end{array}$ & $\begin{array}{l}\text { Arner, Mejhert, } \\
\text { Kulyté, Balwierz } \\
\text { et al. [61] }\end{array}$ \\
\hline GSE24883 & $\begin{array}{l}\text { Worsening of } \\
\text { Obesity and } \\
\text { Metabolic Status } \\
\text { Yields Similar } \\
\text { Molecular } \\
\text { Adaptations_- } \\
\text { Subcutaneous and } \\
\text { Visceral Adipose } \\
\text { Tissue }\end{array}$ & 32 & $\begin{array}{l}\text { Agilent-014850 } \\
\text { Whole Human } \\
\text { Genome } \\
\text { Microarray } \\
4 \times 44 \mathrm{~K} \text { G4112F } \\
\text { (Feature } \\
\text { Number } \\
\text { version) }\end{array}$ & $\begin{array}{l}\text { Klimcáková, } \\
\text { Roussel, } \\
\text { Márquez- } \\
\text { Quiñones, } \\
\text { Kovácová et al. } \\
\text { [62] }\end{array}$ \\
\hline
\end{tabular}

Table 2: List of transcriptomic data for initial data set.

detected over all analysis results with the exception of the epigenetic level. The genes DDX50 and MAOB show high ranks in the double weighed transcriptomic- and the microRNA analysis results. ATM and STOX1 were identified by the transcriptomic data and the proteomic data. PRRC2A was found in the genomic- and transcriptomic results.

ATP5O was the most reduced OXPHOS gene in an expression profile in skeletal muscle from patients with T2D in comparison with healthy control subjects [68]. Ronn et al. [69] conducted a twin study, which showed that genetic variations in the ATP5O gene region is associated with mRNA expression in skeletal muscle and glucose increase in young twins. It was shown in a number of respective studies that aging had a negative effect on ATP5O mRNA expression, which also agrees with findings for other OXPHOS genes [70-72]. These findings suggest combinations of genetic and non-genetic factors may shape the reduced expression of ATP5O in obesity-associated T2DM [68], which concurs with our performed integration study [32].

It has been demonstrated that Activin receptor-like kinase 7 (ALK7) is expressed in pancreatic islets and beta-cell lines [73]. In a study by Watanabe et al. [74] it was noticed, that the human insulin promoter was activated in the ALK7 pathway by Smad2, Smad3 and homeobox factor-1 (PDX-1) of pancreas and duodenum. The study results show that one of the direct target genes of Nodal and Activin

\begin{tabular}{|c|c|c|c|c|}
\hline \multirow{2}{*}{ Gene Name } & \multirow{2}{*}{\begin{tabular}{|c|} 
Chromosome \\
Name
\end{tabular}} & \multirow{2}{*}{ Region start } & \multirow{2}{*}{ Region stop } & \multirow{2}{*}{ Score } \\
\hline & & & & \\
\hline ACVR1C & chr2 & $1.58 \mathrm{E}+08$ & $1.59 \mathrm{E}+08$ & 6.1 \\
\hline MIR190B & chr1 & $1.54 \mathrm{E}+08$ & $1.54 \mathrm{E}+08$ & 6.1 \\
\hline ATP5O & chr21 & 35275000 & 35324999 & 5.2 \\
\hline PTK2 & chr8 & $1.42 \mathrm{E}+08$ & $1.42 \mathrm{E}+08$ & 5.2 \\
\hline GULP1 & chr2 & $1.89 \mathrm{E}+08$ & $1.89 E+08$ & 4.6 \\
\hline MCCC1 & chr3 & $1.83 E+08$ & $1.83 \mathrm{E}+08$ & 4.6 \\
\hline TRIM13 & chr13 & 50575000 & 50624999 & 4.6 \\
\hline ATF2 & chr2 & $1.76 \mathrm{E}+08$ & $1.76 \mathrm{E}+08$ & 4.4 \\
\hline ATP5G3 & chr2 & $1.76 \mathrm{E}+08$ & $1.76 \mathrm{E}+08$ & 4.4 \\
\hline MIR933 & chr2 & $1.76 \mathrm{E}+08$ & $1.76 \mathrm{E}+08$ & 4.4 \\
\hline PDIA5 & chr3 & $1.23 E+08$ & $1.23 E+08$ & 4.4 \\
\hline SEC22A & chr3 & $1.23 E+08$ & $1.23 E+08$ & 4.4 \\
\hline CA6 & chr1 & 9000000 & 9049999 & 4.3 \\
\hline PTH2R & chr2 & $2.09 \mathrm{E}+08$ & $2.09 E+08$ & 4.3 \\
\hline ACACB & chr12 & $1.1 \mathrm{E}+08$ & $1.1 \mathrm{E}+08$ & 4.2 \\
\hline ANXA3 & chr4 & 79525000 & 79574999 & 4.2 \\
\hline GAPDH & chr12 & 6625000 & 6674999 & 4.2 \\
\hline IFFO1 & chr12 & 6625000 & 6674999 & 4.2 \\
\hline MYO5A & chr15 & 52575000 & 52624999 & 4.2 \\
\hline MYO5C & chr15 & 52575000 & 52624999 & 4.2 \\
\hline NCAPD2 & chr12 & 6625000 & 6674999 & 4.2 \\
\hline $\mathrm{BACH} 2$ & chr6 & 90900000 & 90949999 & 4.1 \\
\hline CPNE4 & chr3 & $1.31 \mathrm{E}+08$ & $1.32 \mathrm{E}+08$ & 4.1 \\
\hline LMBR1L & chr12 & 49500000 & 49549999 & 4.1 \\
\hline TUBA1B & chr12 & 49500000 & 49549999 & 4.1 \\
\hline CYP39A1 & chr6 & 46600000 & 46649999 & 4 \\
\hline DMD & $\operatorname{chr} X$ & 31325000 & 31374999 & 4 \\
\hline DMD-AS2 & chrX & 31325000 & 31374999 & 4 \\
\hline SLC25A27 & chr6 & 46600000 & 46649999 & 4 \\
\hline AASS & chr7 & $1.22 \mathrm{E}+08$ & $1.22 \mathrm{E}+08$ & 3.9 \\
\hline ANKRD32 & chr5 & 94025000 & 94074999 & 3.9 \\
\hline BIRC2 & chr11 & $1.02 \mathrm{E}+08$ & $1.02 E+08$ & 3.9 \\
\hline BIRC3 & chr11 & $1.02 \mathrm{E}+08$ & $1.02 \mathrm{E}+08$ & 3.9 \\
\hline FAM13B & chr5 & $1.37 \mathrm{E}+08$ & $1.37 \mathrm{E}+08$ & 3.9 \\
\hline FGF2 & chr4 & $1.24 \mathrm{E}+08$ & $1.24 \mathrm{E}+08$ & 3.9 \\
\hline MCTP1 & chr5 & 94025000 & 94074999 & 3.9 \\
\hline AlF1 & chr6 & 31575000 & 31624999 & 3.8 \\
\hline DAPK2 & chr15 & 64200000 & 64249999 & 3.8 \\
\hline PANX1 & chr11 & 93875000 & 93924999 & 3.8 \\
\hline PRRC2A & chr6 & 31575000 & 31624999 & 3.8 \\
\hline SNORA38 & chr6 & 31575000 & 31624999 & 3.8 \\
\hline UQCRHP1 & chr6 & 31575000 & 31624999 & 3.8 \\
\hline
\end{tabular}


Citation: Brettfeld C, Maver A, Aumuller E, Peterlin B, Haslberger AG (2016) Integration and Weighing of Omics Data for Obesity. J Diabetes Metab 7: 690. doi: 10.4172/2155-6156.1000690

Page 5 of 11

\begin{tabular}{|c|c|c|c|c|}
\hline Gene Name & $\begin{array}{c}\text { Chromosome } \\
\text { Name }\end{array}$ & Region start & Region stop & Score \\
\hline ATP5O & chr21 & 35275000 & 35324999 & 7.1 \\
\hline ACVR1C & chr2 & $1.58 \mathrm{E}+08$ & $1.59 \mathrm{E}+08$ & 6.8 \\
\hline GAPDH & chr12 & 6625000 & 6674999 & 6.2 \\
\hline IFFO1 & chr12 & 6625000 & 6674999 & 6.2 \\
\hline NCAPD2 & chr12 & 6625000 & 6674999 & 6.2 \\
\hline ETV6 & chr12 & 11800000 & 12074999 & 5.8 \\
\hline $\mathrm{HADH}$ & chr4 & $1.09 \mathrm{E}+08$ & $1.09 \mathrm{E}+08$ & 5.8 \\
\hline TXNL1 & chr18 & 54275000 & 54349999 & 5.3 \\
\hline ATM & chr11 & $1.08 \mathrm{E}+08$ & $1.08 \mathrm{E}+08$ & 5.2 \\
\hline NPAT & chr11 & $1.08 \mathrm{E}+08$ & $1.08 \mathrm{E}+08$ & 5.2 \\
\hline ATP8A1 & chr4 & 42400000 & 42449999 & 4.9 \\
\hline FAU & chr11 & 64875000 & 64924999 & 4.9 \\
\hline PKD2 & chr4 & 88925000 & 89024999 & 4.9 \\
\hline SHISA3 & chr4 & 42400000 & 42449999 & 4.9 \\
\hline SYVN1 & chr11 & 64875000 & 64924999 & 4.9 \\
\hline TM7SF2 & chr11 & 64875000 & 64924999 & 4.9 \\
\hline VPS51 & chr11 & 64875000 & 64924999 & 4.9 \\
\hline WDR7 & chr18 & 54300000 & 54349999 & 4.9 \\
\hline GLULP4 & chr9 & 34900000 & 34949999 & 4.8 \\
\hline YWHAZP6 & chr9 & 34900000 & 34949999 & 4.8 \\
\hline ZNHIT2 & chr11 & 64875000 & 64924999 & 4.8 \\
\hline AlF1 & chr6 & 31575000 & 31624999 & 4.7 \\
\hline PRRC2A & chr6 & 31575000 & 31624999 & 4.7 \\
\hline SNORA38 & chr6 & 31575000 & 31624999 & 4.7 \\
\hline UQCRHP1 & chr6 & 31575000 & 31624999 & 4.7 \\
\hline CHTOP & chr1 & $1.54 \mathrm{E}+08$ & $1.54 \mathrm{E}+08$ & 4.6 \\
\hline LEF1 & chr4 & $1.09 \mathrm{E}+08$ & $1.09 \mathrm{E}+08$ & 4.6 \\
\hline S100A1 & chr1 & $1.54 \mathrm{E}+08$ & $1.54 \mathrm{E}+08$ & 4.6 \\
\hline ARID3C & chr9 & 34625000 & 34674999 & 4.1 \\
\hline DCN & chr12 & 91550000 & 91599999 & 4.1 \\
\hline EGFL6 & $\operatorname{chr} X$ & 13575000 & 13674999 & 4.1 \\
\hline F11 & chr4 & $1.87 \mathrm{E}+08$ & $1.87 \mathrm{E}+08$ & 4.1 \\
\hline GALT & chr9 & 34625000 & 34674999 & 4.1 \\
\hline GATAD2A & chr19 & 19525000 & 19574999 & 4.1 \\
\hline IRS2 & chr13 & $1.1 \mathrm{E}+08$ & $1.1 \mathrm{E}+08$ & 4.1 \\
\hline KLKB1 & chr4 & $1.87 \mathrm{E}+08$ & $1.87 \mathrm{E}+08$ & 4.1 \\
\hline MASP2 & chr1 & 11075000 & 11124999 & 4.1 \\
\hline MIR640 & chr19 & 19525000 & 19574999 & 4.1 \\
\hline MYO5A & chr15 & 52575000 & 52624999 & 4.1 \\
\hline MYO5C & chr15 & 52575000 & 52624999 & 4.1 \\
\hline RPL30P15 & $\operatorname{chr} X$ & 13575000 & 13624999 & 4.1 \\
\hline SIGMAR1 & chr9 & 34625000 & 34674999 & 4.1 \\
\hline TARDBP & chr1 & 11075000 & 11124999 & 4.1 \\
\hline ADORA1 & chr1 & $2.03 E+08$ & $2.03 E+08$ & 4 \\
\hline AGPAT5 & chr8 & 6600000 & 6649999 & 4 \\
\hline ANG & chr14 & 21150000 & 21199999 & 4 \\
\hline ATP6V1B1 & chr2 & 71150000 & 71199999 & 4 \\
\hline BLOC1S1 & chr12 & 56100000 & 56149999 & 4 \\
\hline CD63 & chr12 & 56100000 & 56149999 & 4 \\
\hline CRLS1 & chr20 & 5975000 & 6024999 & 4 \\
\hline DIMT1 & chr5 & 61675000 & 61724999 & 4 \\
\hline FAM102B & chr1 & $1.09 \mathrm{E}+08$ & $1.09 \mathrm{E}+08$ & 4 \\
\hline INF2 & chr14 & $1.05 \mathrm{E}+08$ & $1.05 \mathrm{E}+08$ & 4 \\
\hline IP011 & chr5 & 61675000 & 61724999 & 4 \\
\hline ITGA7 & chr12 & 56100000 & 56149999 & 4 \\
\hline KIF2A & chr5 & 61675000 & 61724999 & 4 \\
\hline
\end{tabular}

\begin{tabular}{|c|c|c|c|c|}
\hline MCM8 & chr20 & 5975000 & 6024999 & 4 \\
\hline MIR4659A & chr8 & 6600000 & 6649999 & 4 \\
\hline MIR4659B & chr8 & 6600000 & 6649999 & 4 \\
\hline MYOG & chr1 & $2.03 E+08$ & $2.03 E+08$ & 4 \\
\hline MYOZ3 & chr5 & $1.5 \mathrm{E}+08$ & $1.5 \mathrm{E}+08$ & 4 \\
\hline PDIA5 & chr3 & $1.23 E+08$ & $1.23 E+08$ & 4 \\
\hline RAD23B & chr9 & $1.1 \mathrm{E}+08$ & $1.1 \mathrm{E}+08$ & 4 \\
\hline RDH5 & chr12 & 56100000 & 56149999 & 4 \\
\hline RNASE4 & chr14 & 21150000 & 21199999 & 4 \\
\hline SEC22A & chr3 & $1.23 E+08$ & $1.23 \mathrm{E}+08$ & 4 \\
\hline SLC24A6 & chr12 & $1.14 \mathrm{E}+08$ & $1.14 \mathrm{E}+08$ & 4 \\
\hline SLC8A1 & chr2 & 40475000 & 40524999 & 4 \\
\hline SLC8A1-AS1 & chr2 & 40475000 & 40524999 & 4 \\
\hline SYNPO & chr5 & $1.5 \mathrm{E}+08$ & $1.5 \mathrm{E}+08$ & 4 \\
\hline TNMD & $\operatorname{chr} X$ & 99825000 & 99899999 & 4 \\
\hline TPCN1 & chr12 & 1.14E+08 & $1.14 \mathrm{E}+08$ & 4 \\
\hline VAX2 & chr2 & 71150000 & 71199999 & 4 \\
\hline ADAM9 & chr8 & 38850000 & 38899999 & 3.9 \\
\hline BMP2K & chr4 & 79750000 & 79799999 & 3.9 \\
\hline ERGIC2 & chr12 & 29475000 & 29524999 & 3.9 \\
\hline FAR2 & chr12 & 29475000 & 29524999 & 3.9 \\
\hline FGF2 & chr4 & $1.24 \mathrm{E}+08$ & $1.24 \mathrm{E}+08$ & 3.9 \\
\hline GLUL & chr1 & $1.82 \mathrm{E}+08$ & $1.82 \mathrm{E}+08$ & 3.9 \\
\hline LSAMP & chr3 & $1.16 E+08$ & $1.16 \mathrm{E}+08$ & 3.9 \\
\hline MAOB & $\operatorname{chrX}$ & 43675000 & 43724999 & 3.9 \\
\hline MIR208B & chr14 & 23875000 & 23924999 & 3.9 \\
\hline MYH6 & chr14 & 23875000 & 23924999 & 3.9 \\
\hline MYH7 & chr14 & 23875000 & 23924999 & 3.9 \\
\hline NFAT5 & chr16 & 69725000 & 69774999 & 3.9 \\
\hline NQO1 & chr16 & 69725000 & 69774999 & 3.9 \\
\hline OSBPL11 & chr3 & $1.25 \mathrm{E}+08$ & $1.25 E+08$ & 3.9 \\
\hline PYGM & chr11 & 64500000 & 64549999 & 3.9 \\
\hline RASGRP2 & chr11 & 64500000 & 64549999 & 3.9 \\
\hline RNASEH1 & chr2 & 3600000 & 3649999 & 3.9 \\
\hline RPS7 & chr2 & 3600000 & 3649999 & 3.9 \\
\hline SNX4 & chr3 & $1.25 \mathrm{E}+08$ & $1.25 E+08$ & 3.9 \\
\hline TM2D2 & chr8 & 38850000 & 38899999 & 3.9 \\
\hline CR1 & chr1 & $2.08 \mathrm{E}+08$ & $2.08 \mathrm{E}+08$ & 3.8 \\
\hline DUSP14 & chr17 & 35850000 & 35899999 & 3.8 \\
\hline PALLD & chr4 & $1.7 \mathrm{E}+08$ & $1.7 \mathrm{E}+08$ & 3.8 \\
\hline SC5DL & chr11 & $1.21 \mathrm{E}+08$ & $1.21 \mathrm{E}+08$ & 3.8 \\
\hline SEC61A2 & chr10 & 12175000 & 12224999 & 3.8 \\
\hline SYNRG & chr17 & 35850000 & 35899999 & 3.8 \\
\hline TEDDM1 & chr1 & $1.82 \mathrm{E}+08$ & $1.82 \mathrm{E}+08$ & 3.8 \\
\hline ADH1B & chr4 & $1 E+08$ & $1 \mathrm{E}+08$ & 4.1 \\
\hline
\end{tabular}

Table 4: Results transcriptomic and all data (2:1).

$\mathrm{AB}$ signals is the insulin gene in pancreatic beta-cells and that PDX-1 is immediately connected with the ALK7-Smad pathway [74-76].

Prior GADPH was disputed to be involved in neurodegenerative diseases [77] and different types of cancers [78]. Hwang et al. [79] study acknowledges that an important oxidative target of ROS is GAPDH. One of the consequences of oxidative stress is a decrease in cellular ATP levels and blocked glycolysis [80,81], due to the inactivation of the glycolytic enzyme GAPDH.

The gene IFFO1 is a member of the intermediate filament family. Intermediate filaments are proteins which are original components of the cytoskeleton. The members of this gene family are evolutionarily 
Citation: Brettfeld C, Maver A, Aumuller E, Peterlin B, Haslberger AG (2016) Integration and Weighing of Omics Data for Obesity. J Diabetes Metab 7: 690. doi: 10.4172/2155-6156.1000690

Page 6 of 11

\begin{tabular}{|c|c|c|c|c|}
\hline Gene Name & Chromosome Name & Region start & Region stop & Score \\
\hline RAP2B & chr3 & $1.53 \mathrm{E}+08$ & $1.53 \mathrm{E}+08$ & 5.2 \\
\hline ACVR1C & chr2 & $1.58 \mathrm{E}+08$ & $1.58 \mathrm{E}+08$ & 5 \\
\hline ETV6 & chr12 & 11800000 & 11849999 & 4.9 \\
\hline ATP6V1B1 & chr2 & 71150000 & 71199999 & 4.8 \\
\hline VAX2 & chr2 & 71150000 & 71199999 & 4.8 \\
\hline E2F4 & chr16 & 67225000 & 67274999 & 4.7 \\
\hline ELMO3 & chr16 & 67225000 & 67274999 & 4.7 \\
\hline LRRC29 & chr16 & 67225000 & 67274999 & 4.7 \\
\hline MIR328 & chr16 & 67225000 & 67274999 & 4.7 \\
\hline TNMD & $\operatorname{chr} X$ & 99850000 & 99899999 & 4.7 \\
\hline EEF1A2 & chr20 & 62100000 & 62149999 & 4.6 \\
\hline KCNQ2 & chr20 & 62100000 & 62149999 & 4.6 \\
\hline NDUFAF1 & chr15 & 41675000 & 41724999 & 4.6 \\
\hline ATP5O & chr21 & 35275000 & 35324999 & 4.5 \\
\hline HOXB-AS4 & chr17 & 46700000 & 46749999 & 4.5 \\
\hline HOXB9 & chr17 & 46700000 & 46749999 & 4.5 \\
\hline MIR151A & chr8 & $1.42 \mathrm{E}+08$ & $1.42 \mathrm{E}+08$ & 4.5 \\
\hline MIR196A1 & chr17 & 46700000 & 46749999 & 4.5 \\
\hline PHEX & $\operatorname{chr} X$ & 22075000 & 22124999 & 4.5 \\
\hline PTK2 & chr8 & $1.42 \mathrm{E}+08$ & $1.42 \mathrm{E}+08$ & 4.5 \\
\hline GAPDH & chr12 & 6625000 & 6674999 & 4.3 \\
\hline IFFO1 & chr12 & 6625000 & 6674999 & 4.3 \\
\hline NCAPD2 & chr12 & 6625000 & 6674999 & 4.3 \\
\hline ACSS3 & chr12 & 81475000 & 81524999 & 4.2 \\
\hline ATM & chr11 & $1.08 \mathrm{E}+08$ & $1.08 \mathrm{E}+08$ & 4.2 \\
\hline C11orf65 & chr11 & $1.08 \mathrm{E}+08$ & $1.08 \mathrm{E}+08$ & 4.2 \\
\hline C1orf189 & chr1 & $1.54 \mathrm{E}+08$ & $1.54 \mathrm{E}+08$ & 4.2 \\
\hline MFAP3 & chr5 & $1.53 \mathrm{E}+08$ & $1.53 E+08$ & 4.2 \\
\hline MIR190B & chr1 & $1.54 \mathrm{E}+08$ & $1.54 \mathrm{E}+08$ & 4.2 \\
\hline MIR378A & chr5 & $1.49 \mathrm{E}+08$ & $1.49 \mathrm{E}+08$ & 4.2 \\
\hline PPARGC1B & chr5 & $1.49 \mathrm{E}+08$ & $1.49 \mathrm{E}+08$ & 4.2 \\
\hline TPM3 & chr1 & $1.54 \mathrm{E}+08$ & $1.54 \mathrm{E}+08$ & 4.2 \\
\hline ADAM9 & chr8 & 38875000 & 38924999 & 4.1 \\
\hline COL14A1 & chr8 & $1.21 \mathrm{E}+08$ & $1.21 \mathrm{E}+08$ & 4.1 \\
\hline G3BP1 & chr5 & $1.51 \mathrm{E}+08$ & $1.51 \mathrm{E}+08$ & 4.1 \\
\hline HEYL & chr1 & 40100000 & 40149999 & 4 \\
\hline NT5C1A & chr1 & 40100000 & 40149999 & 4 \\
\hline CHTOP & chr1 & $1.54 \mathrm{E}+08$ & $1.54 \mathrm{E}+08$ & 3.9 \\
\hline GPATCH2 & chr1 & $2.18 \mathrm{E}+08$ & $2.18 \mathrm{E}+08$ & 3.9 \\
\hline HNRNPA1 & chr12 & 54675000 & 54724999 & 3.9 \\
\hline MIR143 & chr5 & $1.49 \mathrm{E}+08$ & $1.49 \mathrm{E}+08$ & 3.9 \\
\hline MIR143HG & chr5 & $1.49 \mathrm{E}+08$ & $1.49 \mathrm{E}+08$ & 3.9 \\
\hline MIR145 & chr5 & $1.49 \mathrm{E}+08$ & $1.49 \mathrm{E}+08$ & 3.9 \\
\hline S100A1 & chr1 & $1.54 \mathrm{E}+08$ & $1.54 \mathrm{E}+08$ & 3.9 \\
\hline S100A13 & chr1 & $1.54 \mathrm{E}+08$ & $1.54 \mathrm{E}+08$ & 3.9 \\
\hline SNORD12 & chr20 & 47875000 & 47924999 & 3.9 \\
\hline SNORD12B & chr20 & 47875000 & 47924999 & 3.9 \\
\hline SNORD12C & chr20 & 47875000 & 47924999 & 3.9 \\
\hline SPATA17 & chr1 & $2.18 \mathrm{E}+08$ & $2.18 \mathrm{E}+08$ & 3.9 \\
\hline YWHAZP6 & chr9 & 34900000 & 34949999 & 3.9 \\
\hline ZNFX1 & chr20 & 47875000 & 47924999 & 3.9 \\
\hline ZNFX1- & chr20 & 47875000 & 47924999 & 3.9 \\
\hline \multicolumn{5}{|l|}{ AS1 } \\
\hline ABCF1 & chr6 & 30550000 & 30599999 & 3.8 \\
\hline ABCF1 & chr6 & 30550000 & 30599999 & 3.8 \\
\hline COPZ1 & chr12 & 54675000 & 54724999 & 3.8 \\
\hline EPS15 & chr1 & 51975000 & 52024999 & 3.8 \\
\hline
\end{tabular}

\begin{tabular}{|c|c|c|c|c|}
\hline GLULP4 & chr9 & 34900000 & 34949999 & 3.8 \\
\hline IARS2 & chr1 & $2.2 \mathrm{E}+08$ & $2.2 \mathrm{E}+08$ & 3.8 \\
\hline MIR194-1 & chr1 & $2.2 \mathrm{E}+08$ & $2.2 \mathrm{E}+08$ & 3.8 \\
\hline MIR215 & chr1 & $2.2 \mathrm{E}+08$ & $2.2 \mathrm{E}+08$ & 3.8 \\
\hline MIR877 & chr6 & 30550000 & 30599999 & 3.8 \\
\hline NFE2 & chr12 & 54675000 & 54724999 & 3.8 \\
\hline PPP1R10 & chr6 & 30550000 & 30599999 & 3.8 \\
\hline
\end{tabular}

Table 5: Results proteomic and all data (2:1).

\begin{tabular}{|c|c|c|c|c|}
\hline Gene Name & $\begin{array}{c}\text { Chromosome } \\
\text { Name }\end{array}$ & Region start & Region stop & Score \\
\hline ATP5O & chr21 & 35275000 & 35324999 & 6.1 \\
\hline CDCP1 & chr3 & 45175000 & 45224999 & 5.3 \\
\hline GAPDH & chr12 & 6625000 & 6674999 & 5.3 \\
\hline IFFO1 & chr12 & 6625000 & 6674999 & 5.3 \\
\hline NCAPD2 & chr12 & 6625000 & 6674999 & 5.3 \\
\hline RAB21 & chr12 & 72175000 & 72224999 & 5.3 \\
\hline BTK & $\operatorname{chrX}$ & 100625000 & $1.01 \mathrm{E}+08$ & 5.2 \\
\hline RPL36A & $\operatorname{chr} X$ & 100625000 & $1.01 \mathrm{E}+08$ & 5.2 \\
\hline GATAD2A & chr19 & 19525000 & 19574999 & 5 \\
\hline MIR640 & chr19 & 19525000 & 19574999 & 5 \\
\hline OXSR1 & chr3 & 38250000 & 38299999 & 5 \\
\hline ADH1B & chr4 & 100225000 & $1 \mathrm{E}+08$ & 4.9 \\
\hline CD99 & $\operatorname{chr} X$ & 2600000 & 2649999 & 4.7 \\
\hline EYA4 & chr6 & 133700000 & $1.34 \mathrm{E}+08$ & 4.7 \\
\hline FAM227B & chr15 & 49725000 & 49774999 & 4.7 \\
\hline FGF7 & chr15 & 49725000 & 49774999 & 4.7 \\
\hline sox5 & chr12 & 24075000 & 24124999 & 4.7 \\
\hline ACVR1C & chr2 & 158425000 & $1.58 \mathrm{E}+08$ & 4.6 \\
\hline $\mathrm{ABCC} 1$ & chr16 & 16225000 & 16274999 & 4.4 \\
\hline$A B C C 6$ & chr16 & 16225000 & 16274999 & 4.4 \\
\hline ANGPT1 & chr8 & 108275000 & $1.08 \mathrm{E}+08$ & 4.4 \\
\hline MAOB & $\operatorname{chrX}$ & 43675000 & 43724999 & 4.4 \\
\hline PFKFB4 & chr3 & 48575000 & 48624999 & 4.4 \\
\hline UCN2 & chr3 & 48575000 & 48624999 & 4.4 \\
\hline PDE4DIP & chr1 & 144950000 & $1.45 \mathrm{E}+08$ & 4.2 \\
\hline VBP1 & $\operatorname{chrX}$ & 154450000 & $1.54 \mathrm{E}+08$ & 4.2 \\
\hline DDX50 & chr10 & 70650000 & 70699999 & 4.1 \\
\hline FAM49B & chr8 & 130950000 & $1.31 \mathrm{E}+08$ & 4.1 \\
\hline LRP1B & chr2 & 141800000 & $1.42 \mathrm{E}+08$ & 4.1 \\
\hline RELN & chr7 & 103575000 & $1.04 \mathrm{E}+08$ & 4.1 \\
\hline STOX1 & chr10 & 70650000 & 70699999 & 4.1 \\
\hline C8orf74 & chr8 & 10525000 & 10574999 & 3.9 \\
\hline CHST15 & chr10 & 125850000 & $1.26 \mathrm{E}+08$ & 3.9 \\
\hline CYB561 & chr17 & 61500000 & 61549999 & 3.9 \\
\hline PRICKLE2 & chr3 & 64200000 & 64249999 & 3.9 \\
\hline RNA5SP25 & chr8 & 10525000 & 10574999 & 3.9 \\
\hline \multicolumn{5}{|l|}{2} \\
\hline RP1L1 & chr8 & 10525000 & 10574999 & 3.9 \\
\hline TANC2 & chr17 & 61500000 & 61549999 & 3.9 \\
\hline RPL37A & chr2 & 217350000 & $2.17 \mathrm{E}+08$ & 3.8 \\
\hline SCMH1 & chr1 & 41600000 & 41649999 & 3.8 \\
\hline
\end{tabular}

Table 6: Results microRNA and all data (2:1).

and structurally related but the proteins encoded have limited sequence homology, with the exception of the central rod domain. There have been multiple alternatively spliced transcript variants encoding different isoforms found [82]. For example, a protein interaction 


\begin{tabular}{|c|c|c|c|c|}
\hline Gene Name & Chromosome & Region start & Region stop & Score \\
\hline NDUFAF1 & chr15 & 41675000 & 41724999 & 5.6 \\
\hline PTPRJ & chr11 & 48150000 & 48199999 & 4.8 \\
\hline ATP5O & chr21 & 35275000 & 35324999 & 4.5 \\
\hline ACVR1C & chr2 & $1.58 \mathrm{E}+08$ & $1.58 \mathrm{E}+08$ & 4.4 \\
\hline KIAA1467 & chr12 & 13200000 & 13249999 & 4.4 \\
\hline MAP3K5 & chr6 & $1.37 \mathrm{E}+08$ & $1.37 \mathrm{E}+08$ & 4.4 \\
\hline PPP2R3A & chr3 & $1.36 \mathrm{E}+08$ & $1.36 \mathrm{E}+08$ & 4.4 \\
\hline C11orf63 & chr11 & $1.23 E+08$ & $1.23 E+08$ & 4.2 \\
\hline FAM13A & chr4 & 89700000 & 89749999 & 4 \\
\hline GPD1L & chr3 & 32150000 & 32199999 & 4 \\
\hline PBLD & chr10 & 70025000 & 70074999 & 4 \\
\hline RAD23B & chr9 & $1.1 \mathrm{E}+08$ & $1.1 \mathrm{E}+08$ & 4 \\
\hline RGS7 & chr1 & $2.41 \mathrm{E}+08$ & $2.41 \mathrm{E}+08$ & 4 \\
\hline SNTG1 & chr8 & 51350000 & 51399999 & 4 \\
\hline BAI3 & chr6 & 69875000 & 69924999 & 3.9 \\
\hline BMP2K & chr4 & 79825000 & 79874999 & 3.9 \\
\hline C12orf52 & chr12 & $1.14 \mathrm{E}+08$ & $1.14 \mathrm{E}+08$ & 3.9 \\
\hline C16orf74 & chr16 & 85725000 & 85774999 & 3.9 \\
\hline IQCD & chr12 & $1.14 \mathrm{E}+08$ & $1.14 \mathrm{E}+08$ & 3.9 \\
\hline LSAMP & chr3 & $1.16 \mathrm{E}+08$ & $1.16 \mathrm{E}+08$ & 3.9 \\
\hline PAQR3 & chr4 & 79825000 & 79874999 & 3.9 \\
\hline SLC8A1 & chr2 & 40450000 & 40499999 & 3.9 \\
\hline SLC8A1- & chr2 & 40450000 & 40499999 & 3.9 \\
\hline \multicolumn{5}{|l|}{ AS1 } \\
\hline DTNA & chr18 & 32350000 & 32399999 & 3.8 \\
\hline
\end{tabular}

Table 7: Results epigenetic and all data (2:1).

network of alternatively spliced isoforms from brain connects genetic risk factors for autism or neurodegenerative disorders [83].

Non-SMC condensin I complex, subunit D2 (NCAPD2, also known as CNAP1) demonstrated to be one of the two SNPs located in two adjacent genes that was demonstrated to be nominally significant association with Alzheimer's Disease. Interestingly, the other adjacent gene identified was GAPDH [84].

In general, the DEAD box proteins are described by a motif of proteins Asp-Glu-Ala-Asp (DEAD). They are putative RNA helicases. DDX50 is involved in a number of cellular processes including the change of RNA secondary structure such as nuclear and mitochondrial splicing, translation initiation and ribosome and spliceosome construction. On the basis of their distribution, some members of this DEAD box protein family are believed to be involved in embryogenesis, cellular growth and division and spermatogenesis [85].

Monoamine oxidase (MAO) appears in two functional forms: MAO-A and MAO-B. The genes of both protein isoforms exhibits identical exon-intron organization, but have different substrate and inhibitor specificities and are encoded by separate genes that are located tail-to-tail on the $\mathrm{X}$ chromosome. While MAO-A removes serotonine, norepinephrine and is selectively inhibited by clorgyline, the MAO-B is more efficient in degrading phenylethylamine and benzylamine and is selectively inhibited by deprenyl $[86,87]$. Both enzymes are exhibited in various tissues throughout the body with the highest levels of expression in liver. Increased levels of MAO-B mRNA and enzymatic activity have been observed in platelets from patients with Parkinson's and Alzheimer's diseases, however the triggers of enhanced mRNA levels are unknown [88].

ATM was identified in two of our analysis as high scoring gene region. It harbors a SNP (rs11212617) and is located within a large block of linkage disequilibrium that includes also the genes CUL5, C11orf65, ACAT1, NPAT, KDELC2, EXPH5. Ataxia Telangiectasia (A-T) or the Louis Bar Syndrome is caused by a homozygous loss of function mutations in ATM. A-T is a neurodegenerative disorder which is described by loss of muscle coordination and progressive ataxia, immunodeficiency, radio sensitivity and a predisposition to cancer [89]. Also, patients with A-T have been shown to have noticeable insulin resistance and increased risk of diabetes [90,91]. Further, previous reports indicate that inhibition or activation of ATM changes AMPK activation [92-94]. Not one of the other genes have been identified to be associated with diabetes or insulin action at the locus. In the study by Zhou et al. [95] the association of ATM in the glycaemic response to metformin establishes another connection between cancer pathways, T2DM and metformin activation of AMPK.

The high scoring gene STOX1 was exhibited in the analysis results of the double weighed transcriptomic- and proteomic data. Many functions as a DNA binding protein is encoded by this gene. Alterations in this gene are connected with pre-eclampsia/eclampsia 4 (PEE4) and might be also linked to the late on set of Alzheimer's Disease [96].

PRRC2A (Proline-rich and coiled-coil-containing protein 2A) also known as BAT2 has been localized adjacent to genes for TNF alpha and TNF beta. The gene is located within the human major histocompatibility complex class III region. It has microsatellite repeats which are connected with the age-at-onset of insulin-dependent diabetes mellitus and possibly associated with the inflammatory process of pancreatic beta-cell degeneration, which occurs during the establishment of insulin-dependent diabetes mellitus. Also this gene is a candidate gene for the development of rheumatoid arthritis [97].

Even though the identified gene regions could not be linked directly to obesity, 8 of 9 discussed genes were associated either to T2DM or a type of neurodegenerative disease. Several epidemiological studies have indicated that being obese increases the risk of neurodegenerative diseases [98-102] and T2DM. The underlying mechanisms of the association among obesity, T2DM and neurodegenerative diseases are not precisely defined, but some mechanistic insight can be inferred. For example, obesity has been associated with several processes related to the acceleration of aging, including the excessive production of free radicals, oxidation and inflammation [103-106]. In addition, a link between obesity-related complications and neurodegenerative disease have been noted by epidemiological research, [107]. Other studies indicate a link between T2DM and fatty liver disease (NAFLD), the hepatic manifestation of metabolic syndrome [108], with Alzheimer's disease [109]. T2DM patients have twice the occurrence of sporadic Alzheimer's disease than their non-diabetic controls [110,111]. NAFLD is characterized by hepatic triglyceride accumulation without excessive alcohol intake that may lead to cirrhosis and is also associated with raised risks of cardiovascular events and T2DM development $[112,113]$. Reports note that up to $50 \%$ of NAFLD patients may experience mild cognitive impairment [114]. NAFLD pathophysiology is complex, but insulin resistance has a central role in its development and is therefore closely linked to metabolic syndrome and T2DM $[115,116]$. One pathway that is related to cancer, Alzheimer`s disease, autism, schizophrenia, Parkinson, NAFLD and fibrosis is the Wnt signaling pathway, which regulates functions like cell proliferation, polarity, apoptosis, inflammation and differentiation in almost all tissues, including the liver, muscle, kidney and brain [117].

The results of our integration of different OMICs layers indicate 
Citation: Brettfeld C, Maver A, Aumuller E, Peterlin B, Haslberger AG (2016) Integration and Weighing of Omics Data for Obesity. J Diabetes Metab 7: 690. doi: 10.4172/2155-6156.1000690

a) Genomic and all Data $(2: 1)$

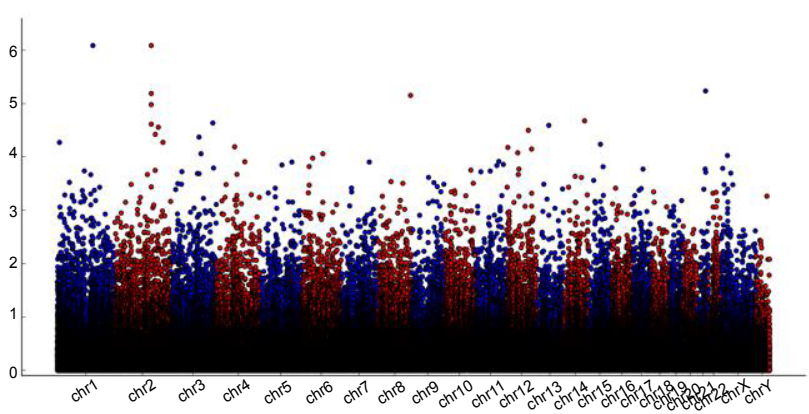

c) Proteomic and all Data (2:1)

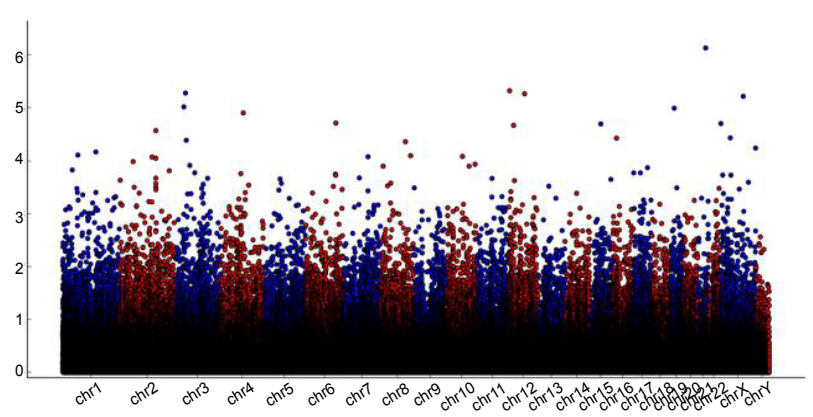

e) Epigenetic and all Data $(2: 1)$

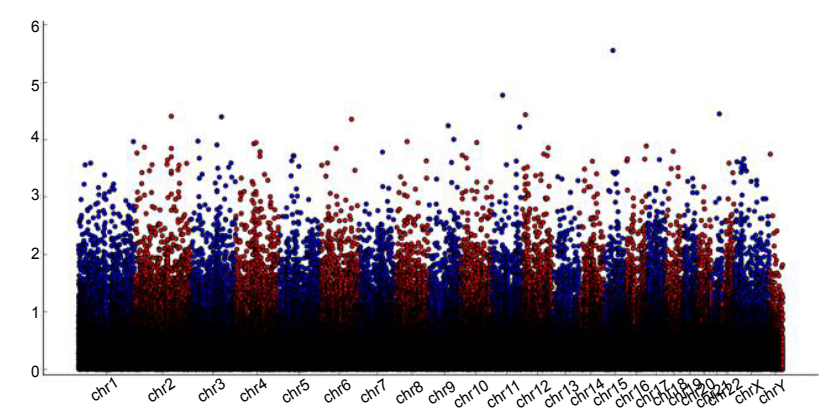

Figure 1: High scoring gene regions. a-e) gives a first impression of our high scoring gene regions. A genome-wide plot displays the distribution of calculated $\mathrm{P}$-values across the genome. X-axis represents locations of the region on genomic backbone and $\mathrm{Y}$-axis represents -log10p estimates of $\mathrm{P}$-values obtained permutation.

potential new gene regions of interest for obesity research, with are in close relation to different types of neurodegenerative disorders.

In our prior study we discussed and pointed out the pros and cons of the position-centric integration approach, we mentioned the choice of region size used for integration, which may result in difficulties by choosing a region too small important long-range interactions may be missed, while choosing a larger region a high amount of false positive genes may be found [32].

Through the weighing of the data we verified on one hand the tool and the consistency of the product data. It shows that the results and b) Expression and all Data $(2: 1)$

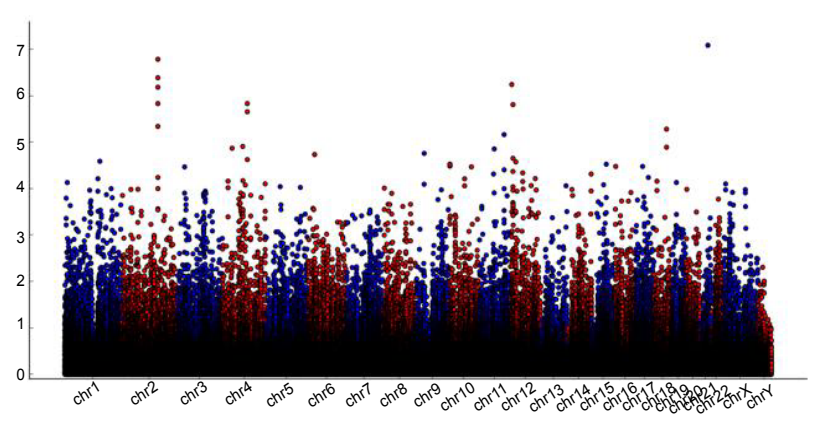

d) RNA and all Data (2:1)

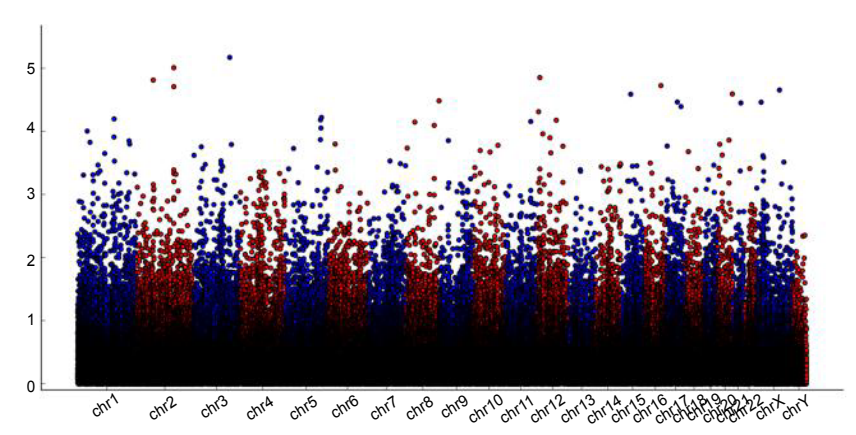

the assessed data itself is consistent on all data levels. However, we have to point out that without the data weighing we would have not discovered which gene regions where identified in all or in multiple approaches that highlight one OMICs level.

\section{Conclusion}

In this study, we applied a new method of positional integrational analysis of different OMIC-layers and a validation step, where we weighed the initial data to confirm prior findings and identify new targets for obesity research. Even though, the ten high ranked and discussed genes could not be directly linked to obesity nine of them 
are associated with $\mathrm{T} 2 \mathrm{DM}$ and neurodegenerative disease. Both disorders show a higher prevalence in obese individuals compared to lean. Thus our study provides a basis for further research to elucidate underlying mechanisms of these associations and identify new targets for preventive and therapeutic interventions.

\section{References}

1. Liddell HG, Scott R (1996) A Greek-English Lexicon.

2. Kolker E, Ozdemir V, Martens L, Hancock W, Anderson G, et al. (2014) Toward more transparent and reproducible omics studies through a common metadata checklist and data publications. OMICS 18: 10-14.

3. Zhao F, Chen Y, Ge S, Yu X, Shao S, et al. (2014) A quantitative analysis of the mass media coverage of genomics medicine in China: a call for science journalism in the developing world. OMICS 18: 222-230.

4. Chakrabarti R (2009) Pharmacotherapy of obesity: emerging drugs and targets. Expert Opin Ther Targets 13: 195-207.

5. Schadt EE, Zhang B, Zhu J (2009) Advances in systems biology are enhancing our understanding of disease and moving us closer to novel disease treatments. Genetica 136: 259-269.

6. Lewis CE, McTigue KM, Burke LE, Poirier P, Eckel RH, et al. (2009) Mortality, health outcomes, and body mass index in the overweight range: a science advisory from the American Heart Association. Circulation 119: 3263-3271.

7. Allison DB, Cui X, Page GP, Sabripour M (2006) Microarray data analysis: from disarray to consolidation and consensus. Nat Rev Genet 7: 55-65.

8. Fontaine KR, Redden DT, Wang C, Westfall AO, Allison DB (2003) Years of life lost due to obesity. JAMA 289: 187-193.

9. Andreasen $\mathrm{CH}$, Andersen G (2009) Gene-environment interactions and obesity--further aspects of genomewide association studies. Nutrition 25 : 998-1003

10. LeRoith D, Novosyadlyy R, Gallagher EJ, Lann D, Vijayakumar A, et al. (2008) Obesity and type 2 diabetes are associated with an increased risk of developing cancer and a worse prognosis; epidemiological and mechanistic evidence. Exp Clin Endocrinol Diabetes 116 Suppl 1: S4-6.

11. Huang PL (2009) A comprehensive definition for metabolic syndrome. Dis Model Mech 2: 231-237.

12. Barrett T, Troup DB, Wilhite SE, Ledoux P, Rudnev D, et al. (2007) NCBI GEO mining tens of millions of expression profiles--database and tools update. Nucleic Acids Res 35: D760-765.

13. Reisin E, Jack AV (2009) Obesity and hypertension: mechanisms, cardio-rena consequences, and therapeutic approaches. Med Clin North Am 93: 733-751.

14. Korner J, Woods SC, Woodworth KA (2009) Regulation of energy homeostasis and health consequences in obesity. Am J Med 122: S12-18.

15. Schoeller DA (2009) The energy balance equation: looking back and looking forward are two very different views. Nutr Rev 67: 249-254.

16. Roche HM, Phillips C, Gibney MJ (2005) The metabolic syndrome: the crossroads of diet and genetics. Proc Nutr Soc 64: 371-377.

17. Remely M, de la Garza AL, Magnet U, Aumueller E, Haslberger AG (2015) Obesity: epigenetic regulation recent observations. Biomol Concepts 6 : 163-175.

18. Bell CG, Walley AJ, Froguel P (2005) The genetics of human obesity. Nat Rev Genet 6: 221-234.

19. Herbert A (2008) The fat tail of obesity as told by the genome. Curr Opin Clin Nutr Metab Care 11: 366-370.

20. Nobrega MA (2013) TCF7L2 and glucose metabolism: time to look beyond the pancreas. Diabetes 62: 706-708.

21. Zhou Y, Park SY, Su J, Bailey K, Ottosson-Laakso E, et al. (2014) TCF7L2 is a master regulator of insulin production and processing. Hum Mol Genet 23 . 6419-6431.

22. Boj SF, van Es JH, Huch M, Li VS, José A, et al. (2012) Diabetes risk gene and Wnt effector Tcf7/2/TCF4 controls hepatic response to perinatal and adult metabolic demand. Cell 151: 1595-1607.

23. Shao W, Wang D, Chiang YT, Ip W, Zhu L, et al. (2013) The Wnt signaling pathway effector TCF7L2 controls gut and brain proglucagon gene expression and glucose homeostasis. Diabetes 62: 789-800

24. Yang J, Loos RJ, Powell JE, Medland SE, Speliotes EK, et al. (2012) FTO genotype is associated with phenotypic variability of body mass index. Nature 490: $267-272$.

25. Thrift AP, Gong J, Peters U, Chang-Claude J, Rudolph A, et al. (2015) Mendelian Randomization Study of Body Mass Index and Colorectal Cancer Risk. Cancer Epidemiol Biomarkers Prev 24: 1024-1031.

26. Locke AE, Kahali B, Berndt SI, Justice AE, Pers TH, et al. (2015) Genetic studies of body mass index yield new insights for obesity biology. Nature 518 : 197-206.

27. Yi F, Brubaker PL, Jin T (2005) TCF-4 mediates cell type-specific regulation of proglucagon gene expression by beta-catenin and glycogen synthase kinase3beta. J Biol Chem 280: 1457-1464.

28. Damcott CM, Pollin TI, Reinhart LJ, Ott SH, Shen H, et al. (2006) Polymorphisms in the transcription factor 7-like 2 (TCF7L2) gene are associated with type 2 diabetes in the Amish: replication and evidence for a role in both insulin secretion and insulin resistance. Diabetes 55: 2654-2659.

29. Saxena R, Gianniny L, Burtt NP, Lyssenko V, Giuducci C, et al. (2006) Common single nucleotide polymorphisms in TCF7L2 are reproducibly associated with type 2 diabetes and reduce the insulin response to glucose in nondiabetic individuals. Diabetes 55: 2890-2895.

30. Dolinoy DC, Huang D, Jirtle RL (2007) Maternal nutrient supplementation counteracts bisphenol A-induced DNA hypomethylation in early development. Proc Natl Acad Sci U S A 104: 13056-13061.

31. Roseboom TJ, Van Der Meulen JH, Ravelli AC, Osmond C, Barker DJ, et al. (2001) Effects of prenatalexposure to the Dutch famine on adult disease in later life: an overview. Molecular and cellular endocrinology 185: 93-98.

32. Haslberger GH, Brettfeld C, Maver A, Aumüller E, Peterlin B (2015) Integration of OMICS Data forObesity. J Diab Obes 2: 1-9.

33. Timpson NJ, Lindgren CM, Weedon MN, Randall J, Ouwehand WH, et al. (2009) Adiposity-related heterogeneity in patterns of type 2 diabetes susceptibility observed in genome-wide association data. Diabetes 58: 505-510.

34. Hindorff LA, Sethupathy P, Junkins HA, Ramos EM, Mehta JP, et al. (2009) Potential etiologic and functional implications of genome-wide association loc for human diseases and traits. Proc Natl Acad Sci U S A 106: 9362-9367.

35. Steinthorsdottir V, Thorleifsson G, Reynisdottir I, Benediktsson R, Jonsdottir T, et al. (2007) A variant in CDKAL1 influences insulin response and risk of type 2 diabetes. Nat Genet 39: 770-775.

36. Johnson AD, O'Donnell CJ (2009) An open access database of genome-wide association results. BMC Med Genet 10: 6.

37. Heard-Costa NL, Zillikens MC, Monda KL, Johansson A, Harris TB, et al. (2009) NRXN3 is a novel locus for waist circumference: a genome-wide association study from the CHARGE Consortium. PLoS Genet 5: e1000539.

38. Cotsapas C, Speliotes EK, Hatoum IJ, Greenawalt DM, Dobrin R, et al. (2009) Common body mass index-associated variants confer risk of extreme obesity. Hum Mol Genet 18: 3502-3507.

39. Weedon MN, Lettre G, Freathy RM, Lindgren CM, Voight BF, et al. (2007) A common variant of HMGA2 is associated with adult and childhood height in the general population. Nat Genet 39: 1245-1250.

40. Frayling TM, Timpson NJ, Weedon MN, Zeggini E, Freathy RM, et al. (2007) A common variant in the FTO gene is associated with body mass index and predisposes to childhood and adult obesity. Science 316: 889-894.

41. Loos RJ, Lindgren CM, Li S, Wheeler E, Zhao JH, et al. (2008) Common variants near MC4R are associated with fat mass, weight and risk of obesity. Nat Genet 40: 768-775.

42. Willer CJ, Speliotes EK, Loos RJ, Li S, Lindgren CM, et al. (2009) Six new loci associated with body mass index highlight a neuronal influence on body weight regulation. Nat Genet 41: 25-34.

43. Thorleifsson G, Walters GB, Gudbjartsson DF, Steinthorsdottir V, Sulem P, et al. (2009) Genome-wide association yields new sequence variants at seven loci that associate with measures of obesity. Nat Genet 41: 18-24.

44. Fox CS, Heard-Costa N, Cupples LA, Dupuis J, Vasan RS, et al. (2007) Genome-wide association to body mass index and waist circumference: the Framingham Heart Study 100K project. BMC Med Genet 8 Suppl 1: S18. 
45. Scuteri A, Sanna S, Chen WM, Uda M, Albai G, et al. (2007) Genome-wide association scan shows genetic variants in the FTO gene are associated with obesity-related traits. PLoS Genet 3: e115.

46. Johansson A, Marroni F, Hayward C, Franklin CS, Kirichenko AV, et al. (2010) Linkage and genome-wide association analysis of obesity-related phenotypes: association of weight with the MGAT1 gene. Obesity (Silver Spring) 18: 803808.

47. Paternoster L, Evans DM, Nohr EA, Holst C, Gaborieau V, et al. (2011) Genome-wide population-based association study of extremely overweight young adults--the GOYA study. PLoS One 6: e24303.

48. Wang K, Li WD, Zhang CK, Wang Z, Glessner JT, et al. (2011) A genome-wide association study on obesity and obesity-related traits. PLoS One 6: e18939.

49. Jiao H, Arner P, Hoffstedt J, Brodin D, Dubern B, et al. (2011) Genome wide association study identifies KCNMA1 contributing to human obesity. BMC Med Genomics 4: 51

50. Ng MC, Hester JM, Wing MR, Li J, Xu J, et al. (2012) Genome-wide association of BMI in African Americans. Obesity (Silver Spring) 20: 622-627.

51. Speliotes EK, Willer CJ, Berndt SI, Monda KL, Thorleifsson G, et al. (2010) Association analyses of 249,796 individuals reveal 18 new loci associated with body mass index. Nat Genet 42: 937-948.

52. Scherag A, Dina C, Hinney A, Vatin V, Scherag S, et al. (2010) Two new Loci for body-weight regulation identified in a joint analysis of genome-wide association studies for early-onset extreme obesity in French and german study groups. PLoS Genet 6: e1000916.

53. Strachan DP, Rudnicka AR, Power C, Shepherd P, Fuller E, et al. (2007) Lifecourse influences on health among British adults: effects of region of residence in childhood and adulthood. Int J Epidemiol 36: 522-531.

54. Dorajoo R, Blakemore Al, Sim X, Ong RT, Ng DP, et al. (2012) Replication of 13 obesity loci among Singaporean Chinese, Malay and Asian-Indian populations. Int J Obes (Lond) 36: 159-163.

55. Lindgren CM, Heid IM, Randall JC, Lamina C, Steinthorsdottir V, et al. (2009) Genome-wide association scan meta-analysis identifies three Loci influencing adiposity and fat distribution. PLoS Genet 5: e1000508.

56. Hardy OT, Perugini RA, Nicoloro SM, Gallagher-Dorval K, Puri V, et al. (2011) Body mass index-independent inflammation in omental adipose tissue associated with insulin resistance in morbid obesity. Surg Obes Relat Dis 7: $60-67$

57. Keller P, Gburcik V, Petrovic N, Gallagher IJ, Nedergaard J, et al. (2011) Gene-chip studies of adipogenesis-regulated microRNAs in mouse primary adipocytes and human obesity. BMC Endocr Disord 11: 7.

58. MacLaren RE, Cui W, Lu H, Simard S, Cianflone K (2010) Association of adipocyte genes with ASP expression: a microarray analysis of subcutaneous and omental adipose tissue in morbidly obese subjects. BMC Med Genomics 3: 3

59. Park JJ, Berggren JR, Hulver MW, Houmard JA, Hoffman EP (2006) GRB14 GPD1, and GDF8 as potential network collaborators in weight loss-induced improvements in insulin action in human skeletal muscle. Physiol Genomics 27: 114-121.

60. Pihlajamäki J, Boes T, Kim EY, Dearie F, Kim BW, et al. (2009) Thyroid hormone-related regulation of gene expression in human fatty liver. $\mathrm{J}$ Clin Endocrinol Metab 94: 3521-3529.

61. Arner E, Mejhert N, Kulyté A, Balwierz PJ, Pachkov M, et al. (2012) Adipose tissue microRNAs as regulators of CCL2 production in human obesity. Diabetes 61: 1986-1993

62. Klimcáková E, Roussel B, Márquez-Quiñones A, Kovácová Z, Kováciková $\mathrm{M}$, et al. (2011) Worsening of obesity and metabolic status yields similar molecular adaptations in human subcutaneous and visceral adipose tissue: decreased metabolism and increased immune response. J Clin Endocrinol Metab 96: E73-82.

63. Abu-Farha M, Tiss A Abubaker J, Khadir A, Al-Ghimlas F, et al. (2013) Proteomics analysis of human obesity reveals the epigenetic factor HDAC4 as a potential target for obesity. PLoS One 8: e75342.

64. Barres R, Kirchner H, Rasmussen M, Yan J, Kantor FR, et al. (2013) Weight loss after gastric bypass surgery in human obesity remodels promoter methylation. Cell Rep 3: 1020-1027.
65. Maver A, Peterlin B (2011) Positional integratomic approach in identification of genomic candidate regions for Parkinson's disease. Bioinformatics 27 1971-1978.

66. Ashburner M, Ball CA, Blake JA, Botstein D, Butler H, et al. (2000) Gene ontology: tool for the unification of biology. The Gene Ontology Consortium. Nat Genet 25: 25-29.

67. Ogata H, Goto S, Sato K, Fujibuchi W, Bono H, et al. (1999) KEGG: Kyoto Encyclopedia of Genes and Genomes. Nucleic Acids Res 27: 29-34.

68. Mootha VK, Lindgren CM, Eriksson KF, Subramanian A, Sihag S, et al. (2003) PGC-1alpha-responsive genes involved in oxidative phosphorylation are coordinately downregulated in human diabetes. Nat Genet 34: 267-273.

69. Rönn T, Poulsen P, Tuomi T, Isomaa B, Groop L, et al. (2009) Genetic variation in ATP5O is associated with skeletal muscle ATP50 mRNA expression and glucose uptake in young twins. PLoS One 4: e4793.

70. Ling C, Poulsen P, Simonsson S, Rönn T, Holmkvist J, et al. (2007) Genetic and epigenetic factors are associated with expression of respiratory chain component NDUFB6 in human skeletal muscle. J Clin Invest 117: 3427-3435.

71. Rönn T, Poulsen P, Hansson O, Holmkvist J, Almgren P, et al. (2008) Age influences DNA methylation and gene expression of COX7A1 in human skeletal muscle. Diabetologia 51: 1159-1168.

72. Trounce I, Byrne E, Marzuki S (1989) Decline in skeletal muscle mitochondria respiratory chain function: possible factor in ageing. Lancet 1: 637-639.

73. Bertolino P, Holmberg R, Reissmann E, Andersson O, Berggren PO, et al (2008) Activin B receptor ALK7 is a negative regulator of pancreatic beta-cell function. Proc Natl Acad Sci U S A 105: 7246-7251.

74. Watanabe R, Shen ZP, Tsuda K, Yamada Y (2008) Insulin gene is a targe in activin receptor-like kinase 7 signaling pathway in pancreatic beta-cells. Biochem Biophys Res Commun 377: 867-872.

75. Lafontan M, Langin D (2009) Lipolysis and lipid mobilization in human adipose tissue. Prog Lipid Res 48: 275-297.

76. Farmer SR (2006) Transcriptional control of adipocyte formation. Cell Metab 4: 263-273.

77. Allen M, Cox C, Belbin O, Ma L, Bisceglio GD, et al. (2012) Association and heterogeneity at the GAPDH locus in Alzheimer's disease. Neurobiol Aging 33: 203

78. Krasnov GS, Dmitriev AA, Snezhkina AV, Kudryavtseva AV (2013) Deregulation of glycolysis in cancer: glyceraldehyde-3-phosphate dehydrogenase as a therapeutic target. Expert Opin Ther Targets 17: 681-693.

79. Hwang NR, Yim SH, Kim YM, Jeong J, Song EJ, et al. (2009) Oxidative modifications of glyceraldehyde-3-phosphate dehydrogenase play a key role in its multiple cellular functions. Biochem J 423: 253-264.

80. Colussi C, Albertini MC, Coppola S, Rovidati S, Galli F, et al. (2000) H2O2 induced block of glycolysis as an active ADP-ribosylation reaction protecting cells from apoptosis. FASEB J 14: 2266-2276.

81. Spragg RG, Hinshaw DB, Hyslop PA, Schraufstätter IU, Cochrane CG (1985) Alterations in adenosine triphosphate and energy charge in cultured endothelia and P388D1 cells after oxidant injury. J Clin Invest 76: 1471-1476.

82. Omary MB, Coulombe PA, McLean WH (2004) Intermediate filament proteins and their associated diseases. N Engl J Med 351: 2087-2100.

83. Corominas R, Yang X, Lin GN, Kang S, Shen Y, et al. (2014) Protein interaction network of alternatively spliced isoforms from brain links genetic risk factors for autism. Nat Commun 5: 3650

84. Lee JH, Cheng R, Rogaeva E, Meng Y, Stern Y, et al. (2008) Further examination of the candidate genes in chromosome 12p13 locus for late-onset Alzheimer disease. Neurogenetics 9: 127-138.

85. Valdez BC, Yang H, Hong E, Sequitin AM (2002) Genomic structure of newly identified paralogue of RNA helicase II/Gu: detection of pseudogenes and multiple alternatively spliced mRNAs. Gene 284: 53-61.

86. Shih JC, Grimsby J, Chen K (1990) The expression of human MAO-A and B genes. J Neural Transm Suppl 32: 41-47.

87. Grimsby J, Lan NC, Neve R, Chen K, Shih JC (1990) Tissue distribution of human monoamine oxidase A and B mRNA. J Neurochem 55: 1166-1169.

88. Ho SL, Kapadi AL, Ramsden DB, Williams AC (1995) An allelic association study of monoamine oxidase B in Parkinson's disease. Ann Neurol 37: 403-405. 
Citation: Brettfeld C, Maver A, Aumuller E, Peterlin B, Haslberger AG (2016) Integration and Weighing of Omics Data for Obesity. J Diabetes Metab 7: 690. doi: 10.4172/2155-6156.1000690

Page 11 of 11

89. Boder E (1985) Ataxia-telangiectasia: an overview. Kroc Found Ser 19: 1-63.

90. Schalch DS, McFarlin DE, Barlow MH (1970) An unusual form of diabetes mellitus in ataxia telangiectasia. N Engl J Med 282: 1396-1402.

91. Bar RS, Levis WR, Rechler MM, Harrison LC, Siebert C, et al. (1978) Extreme insulin resistance in ataxia telangiectasia: defect in affinity of insulin receptors. N Engl J Med 298: 1164-1171.

92. Sun Y, Connors KE, Yang DQ (2007) AICAR induces phosphorylation of AMPK in an ATM-dependent, LKB1-independent manner. Mol Cell Biochem 306: 239245.

93. Fu X, Wan S, Lyu YL, Liu LF, Qi H (2008) Etoposide induces ATM-dependent mitochondrial biogenesis through AMPK activation. PLoS One 3: e2009.

94. Sanli T, Rashid A, Liu C, Harding S, Bristow RG, et al. (2010) lonizing radiation activates AMP-activated kinase (AMPK): a target for radiosensitization of human cancer cells. Int J Radiat Oncol Biol Phys 78: 221-229.

95. GoDARTS and UKPDS Diabetes Pharmacogenetics Study Group1; Wellcome Trust Case Control Consortium 2, Zhou K, Bellenguez C, Spencer CC, Bennett AJ, et al. (2011) Common variants near ATM are associated with glycemic response to metformin in type 2 diabetes. Nat Genet 43: 117-120.

96. van Dijk M, van Bezu J, Poutsma A, Veerhuis R, Rozemuller AJ, et al. (2010) The pre-eclampsia gene STOX1 controls a conserved pathway in placenta and brain upregulated in late-onset Alzheimer's disease. J Alzheimers Dis 19: 673679.

97. Singal DP, Li J, Zhu Y (2000) HLA class III region and susceptibility to rheumatoid arthritis. Clin Exp Rheumatol 18: 485-491.

98. Anstey KJ, Cherbuin N, Budge M, Young J (2011) Body mass index in midlife and late-life as a risk factor for dementia: a meta-analysis of prospective studies. Obes Rev 12: e426-437.

99. Jauch-Chara K, Oltmanns KM (2014) Obesity--a neuropsychological disease? Systematic review and neuropsychological model. Prog Neurobiol 114: 84-101.

100. Kivipelto M, Ngandu T, Fratiglioni L, Viitanen M, Kåreholt I, et al. (2005) Obesity and vascular risk factors at midlife and the risk of dementia and Alzheimer disease. Arch Neurol 62: 1556-1560.

101. Whitmer RA, Gunderson EP, Quesenberry CP Jr, Zhou J, Yaffe K (2007) Body mass index in midlife and risk of Alzheimer disease and vascular dementia. Curr Alzheimer Res 4: 103-109.

102. Xu WL, Atti AR, Gatz M, Pedersen NL, Johansson B, et al. (2011) Midlife overweight and obesity increase late-life dementia risk: a population-based twin study. Neurology 76: 1568-1574.

103. Bhat NR (2010) Linking cardiometabolic disorders to sporadic Alzheimer's disease: a perspective on potential mechanisms and mediators. J Neurochem 115: 551-562.

104.Dandona P, Aljada A, Chaudhuri A, Mohanty P, Garg R (2005) Metabolic syndrome: a comprehensive perspective based on interactions between obesity, diabetes, and inflammation. Circulation 111: 1448-1454.

105. Haffner SM (2006) The metabolic syndrome: inflammation, diabetes mellitus, and cardiovascular disease. Am J Cardiol 97: 3A-11A

106. Miranda S, Opazo C, Larrondo LF, Muñoz FJ, Ruiz F, et al. (2000) The role of oxidative stress in the toxicity induced by amyloid beta-peptide in Alzheimer's disease. Prog Neurobiol 62: 633-648.

107. Ashrafian H, Harling L, Darzi A, Athanasiou T (2013) Neurodegenerative disease and obesity: what is the role of weight loss and bariatric interventions? Metab Brain Dis 28: 341-353.

108. Tarantino G, Finelli C (2013) What about non-alcoholic fatty liver disease as a new criterion to define metabolic syndrome? World J Gastroenterol 19: 3375-3384

109. de la Monte SM, Neusner A, Chu J, Lawton M (2009) Epidemilogical trends strongly suggest exposures as etiologic agents in the pathogenesis of sporadic Alzheimer's disease, diabetes mellitus, and non-alcoholic steatohepatitis. J Alzheimers Dis 17: 519-529.

110. Kravitz E, Schmeidler J, Beeri MS (2013) Type 2 diabetes and cognitive compromise: potential roles of diabetes-related therapies. Endocrinol Metab Clin North Am 42: 489-501.

111. Vignini A, Giulietti A, Nanetti L, Raffaelli F, Giusti L, et al. (2013) Alzheimer's disease and diabetes: new insights and unifying therapies. Curr Diabetes Rev 9: $218-227$

112. Anstee QM, Day CP (2013) The genetics of NAFLD. Nat Rev Gastroentero Hepatol 10: 645-655.

113. Anstee QM, Targher G, Day CP (2013) Progression of NAFLD to diabetes mellitus, cardiovascular disease or cirrhosis. Nat Rev Gastroenterol Hepato 10: 330-344.

114. Newton JL (2010) Systemic symptoms in non-alcoholic fatty liver disease. Dig Dis 28: 214-219.

115. Arrese M (2010) Nonalcoholic fatty liver disease: liver disease: an overlooked complication of diabetes mellitus. Nat Rev Endocrinol 6: 660-661.

116. Von Bernhardi R, Zanlungo S, Arrese M, Arteaga A, Rigotti A (2010) The metabolic syndrome: from an aggravating condition to a pathogenic risk factor for chronic diseases. Rev Med Chil 138: 1012-1019.

117. Nusse R (2012) Wnt signaling. Cold Spring Harb Perspect Biol 4: 1-3. 